\title{
EFFECT OF OPERATIONAL CONDITIONS ON REMOVAL OF 4-CHLOROPHENOL IN WATER USING UV/NiO PROCESS
}

\author{
ASSADI A. ${ }^{1}$ \\ ALIMORADZADEH R. ${ }^{1,{ }^{*}}$ \\ NASSERI S. ${ }^{2}$ \\ MEHRASBI M.R. ${ }^{1}$
}

\author{
${ }^{1}$ Department of Environmental Health Engineering \\ Zanjan University of Medical Sciences, Zanjan, Iran \\ ${ }^{2}$ Department of Environmental Health Engineering \\ School of Public Health and Center for Water Quality Research \\ Institute for Environmental Research \\ Tehran University of Medical Sciences, Tehran, Iran
}

Received: 22/07/2014

Accepted: 26/10/2014

Available online: 09/12/2014 *to whom all correspondence should be addressed: e-mail: r.alimoradzade@gmail.com

\section{ABSTRACT}

This study present the removal of 4-chlorophenol (4-CP) from water by nickel oxide (NiO) nanoparticles. Photodegradation was compared using different processes in a batch reactor with medium-pressure mercury lamp irradiation. The effects of operating conditions such as feed concentration of reactants, catalyst load, $\mathrm{pH}$, and half-life time on photodegradation system were evaluated. The results showed that photodegradation using $\mathrm{UV} / \mathrm{NiO}$ system in the presence of $\mathrm{H}_{2} \mathrm{O}_{2}$ were much more effective than using either $\mathrm{UV} / \mathrm{H}_{2} \mathrm{O}_{2}$ or UV/NiO processes. The optimum conditions for the complete degradation of 4-CP were achieved at a neutral pH, with $0.2 \mathrm{~mol} \mathrm{I}^{-1} \mathrm{H}_{2} \mathrm{O}_{2}$, and $0.05 \mathrm{~g} \mathrm{l}^{-1}$ of NiO. However, no significant $\mathrm{pH}$ effects were observed in the range of 4-10. Also, the best TOC removal and $\mathrm{Cl}^{-}$ions formation results were achieved by combined system with 48 and $80 \%$, respectively. The illuminated $\mathrm{NiO}$ nanoparticles had lower influence on the degradation of 4-CP but dramatically promoted the mineralization of 4-CP. For all these reactions, the degradation rates are evaluated by determining their first-order rate constants and half-life times. The reaction rate constants ranged from $0.0003 \mathrm{~min}^{-1}$ by direct photolysis to $0.029 \mathrm{~min}^{-1}$ and $0.083 \mathrm{~min}^{-1}$ using $\mathrm{UV} / \mathrm{NiO}$ in absent and presence of $\mathrm{H}_{2} \mathrm{O}_{2}$, respectively.

Keywords: 4-chlorophenol, UV light, Nickel oxide, Hydrogen peroxide

\section{Introduction}

Increasing demand and shortage of water sources due to the rapid development of industrialization, population growth and long-term droughts have become an issue worldwide. With this growing demand, there is a need to increase new water and wastewater treatment processes to reduce negative effects on water bodies.

Among the methods considered, heterogeneous photocatalytic oxidation systems (HPOs) can efficiently eliminate persistent organic pollutants at a low cost energy (Stasinakis, 2008; Catrinescu et al., 2011). Photocatalytic oxidation processes concern with photoactivated metal oxides as semiconductors to remove contaminants in aqueous environment (Lo et al., 2004). In the photocatalytic systems, the UV irradiation of metal oxides upon incidence of photon with an energy higher than its band gap energy results in the formation

Assadi A., Alimoradzadeh R., Nasseri S. and Mehrasbi M.R. (2015), Effect of operational conditions on removal of 4-chlorophenol in water using UV/NiO process, Global NEST Journal, 17(1), 118-129. 
of electrons $\left(\mathrm{e}^{-}\right)$in the conduction band and positive holes $\left(\mathrm{h}^{+}\right)$in the valence band. The hole can either oxidize a compound directly or react with electron donors like water to form $\mathrm{OH}$ radicals, which react with pollutants and mineralize them to $\mathrm{CO}_{2}$ and $\mathrm{H}_{2} \mathrm{O}_{2}$ (Aguedach et al., 2005; Goel et al., 2010).

Chlorophenols are hazardous chemicals and generally categorized as non-biodegradable pollutants. Continuous consumption of drinking water contaminated with chlorophenols can affect human health. A representative of this class of compounds is 4-chlorophenol (4-CP). Sources of this compound include industrial effluents, such as petroleum refining, and production of pesticides, paint, plastic, resin, textile, iron, solvent, pharmaceutics and wood preserving chemicals and named as one of the priority pollutants by the US Environmental Protection Agency (EPA) and the European Union (EU). The permissible limit of 4-CP in drinking water supply is $0.5 \mathrm{mg} \mathrm{l}^{-1}$ (Pera-Titus et al., 2004; Pi et al., 2007; Movahedyan et al., 2008; Gomez et al., 2009; Neppolian et al., 2011; Olaniran and Igbinosa, 2011). Due to 4-CP high toxicity and persistence in the environment, attention has been focused on its removal from the aqueous media.

Titanium dioxide ( $\mathrm{TiO} 2$ ) has received the greatest interest in research of photocatalytic process due to chemical and thermal stability or resistance to chemical breakdown, low cost and their strong mechanical properties have promoted its wide application in photocatalytic water treatment (Laoufi et al., 2008; Gaya et al., 2009; Ghosh et al., 2009). The main pitfall of $\mathrm{TiO}_{2}$ is based on the economy of the extensive use for largescale facilities, and, in some cases, on the low mineralization level achieved, requiring a final polishing stage (Gimeno et al., 2005). There is renewed effort to study for more reliable semiconductors (Li et al., 2009). Other semiconductor catalsts has demonstrated its efficiency in degrading a wide range of chlorophenols. (Stoyanova et al., 2003; Lai et al., 2008; Stoyanova and Christoskova, 2011). NiO is a vital semiconductor widely used as a catalyst with extraordinary electrical, thermal, catalytic, and redox properties (Stoyanova et al., 2006; Devulapelli and Sahle-Demessie, 2008).

Most attracting features of $\mathrm{NiO}$ are excellent durability and electrochemical stability. Reported band gap energy value for the nickel oxide is in the range of 3.4-3.8 eV. This suggests that the optical transition in NiO takes place through direct inter-band transition (Patil and Kadam, 2002). Also, NiO can act as a promoter for the generation of $\mathrm{OH}$ radicals (Zhang et al., 2009). The results of research work have proved that the recovered nickel oxides particles had a catalytic activity as well as the properties of the product before use (He et al., 2010). Recently, photocatalytic degradation of organic pollutants using $\mathrm{NiO}$ particles has gained considerable attention (Stoyanova et al., 2003; Lai et al., 2007; Lai et al., 2011). The drawback of NiO particles might be the influence on the amount of mineralization and the presence of nanoparticles in the effluent. The main aim of this study was to examine effects of operational parameters for the removal of 4-CP under different irradiation processes such as direct photolysis (UV alone), UV/ $\mathrm{H}_{2} \mathrm{O}_{2}, \mathrm{UV} / \mathrm{NiO}$, and $\mathrm{UV} / \mathrm{NiO} / \mathrm{H}_{2} \mathrm{O}_{2}$ in the presence and absent of $\mathrm{NiO}$ nanoparticles. Also, the mineralization of $4-\mathrm{CP}$ and the first-order rate constants were determined under different conditions.

\section{Materials and methods}

\subsection{Material}

4- $\mathrm{CP}$ (purity 99\%) and $\mathrm{H}_{2} \mathrm{O}_{2}(30 \%, w / v)$ reagents were purchased from Merck Co. NiO nano powder (99.8\% purity and $<50 \mathrm{~nm}$ particle size) was obtained from Sigma-Aldrich. Other chemicals were of analytical grade and were used without further purification. Deionized water was used throughout this present study. The $\mathrm{pH}$ of solution was adjusted using $\mathrm{NaOH}$ and $\mathrm{H}_{2} \mathrm{SO}_{4}$, where needed.

\subsection{Experimental Set-up}

The photocatalytic experiments were performed in a batch reactor. It consisted of a cylindrical glass reactor ( 2 I total volume) with an inner diameter and height of $11 \mathrm{~cm}$ and $16 \mathrm{~cm}$, respectively. In each experiment, the 
reactor was filled with $1000 \mathrm{~mL}$ of an aqueous solution of 4-CP with predetermined $\mathrm{pH}$ value. Irradiation was achieved by using UV lamp of $150 \mathrm{~W}$ (medium-pressure lamp) with main emission wavelength at $247 \mathrm{~nm}$. Also, the intensity of it is $1020 \mu \mathrm{W} \mathrm{cm}$ in the distance of $15 \mathrm{~cm}$. The UV lamp was located vertically in the center of reactor within a double-wall cooling system.

The reactor was filled with the reaction mixture containing constant concentration of $100 \mathrm{mg} \mathrm{l}^{-1} 4-\mathrm{CP}$. The reaction was performed at neutral $\mathrm{pH}$ except for a few runs to evaluate $\mathrm{pH}$ effects on the reaction rate. For runs $\mathrm{UV} / \mathrm{H}_{2} \mathrm{O}_{2}, \mathrm{UV} / \mathrm{NiO}, \mathrm{UV} / \mathrm{NiO} / \mathrm{H}_{2} \mathrm{O}_{2}$ system, the $\mathrm{pH}$ value of solution was adjusted at the desired value before start-up, and then a given amount of $\mathrm{NiO}$ was added. The nanocatalyst was mixed very well with 4-CP before the addition of given volume ofoxidant. The time at which UV lamp was turned on was considered time zero. All experiments have been done in $60 \mathrm{~min}$. The initial concentrations of $\mathrm{H}_{2} \mathrm{O}_{2}$ and $\mathrm{NiO}$ varied in the range of $0.005-0.4 \mathrm{~mol} \mathrm{I}^{-1}$ and $0.025-0.2 \mathrm{gl}^{-1}$, respectively.

\subsection{Analysis}

Samples were taken from the sample port of the reactor at predetermined time intervals. Potential reactions with hydrogen peroxide and hydroxyl radicals in the samples were quenched by using $6 \mathrm{M} \mathrm{NaOH}$ solution. The samples were filtered by syringe membrane filter $(0.45 \mu \mathrm{m}$ pore-size) to remove $\mathrm{NiO}$ particles. Analyses of initial and remaining concentrations of 4-CP were determined with a Knauer HPLC instrument with a reversed phase C18 column (Erouphere $250 \times 4.6 \mathrm{~mm}$ ). The injected volume of reaction solution was $20 \mu \mathrm{L}$. The mobile phase was prepared by methanol and deionized water (containing 2 percent acetic acid) in 52/48 (V/V) ratio

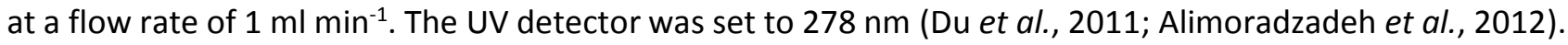

Ion chromatography (881 Compact IC pro, Metrohm) equipped with a Metrosep ASUPP4 column $(250 \times 4.0$ $\mathrm{mm}$ ) was employed for the analysis of chloride ion concentrations in aqueous solution using $\mathrm{NaCl}$ as a standard. The mobile phase of a mixture of $2.5 \mathrm{mM} \mathrm{Na}_{2} \mathrm{CO}_{3}$ and $2.4 \mathrm{mM} \mathrm{NaHCO}_{3}$ was used at a flow rate of $0.7 \mathrm{ml} \mathrm{min} \mathrm{m}^{-1}$. The volume of each sample was $20 \mu \mathrm{L}$. The level of quantitation (LOQ) for determination of chloride ion was $25 \mathrm{\mu g} \mathrm{l}^{-1}$. The total organic carbon (TOC) was measured by means of a Dohrmann DC-190 (Rosemount Analytical Inc., Santa Clara, CA, USA) high-temperature TOC analyzer based on the combustioninfrared method. All experiments have been performed once except for quality analysis and pretests. Calibration curve at six concentration levels were prepared from working solutions containing the 4-CP in the range of $0.1-100 \mathrm{mg} \mathrm{l}^{-1}\left(\mathrm{R}^{2}=0.999\right)$. Detection limit of this method for determination of $4-\mathrm{CP}$ is $0.02 \mathrm{mg} \mathrm{l}^{-1}$ and the relative standard error (RSD) did not exceed more than 0.2 percent based on triplicate.

The surface of $\mathrm{NiO}$ particles was observed with a scanning electron microscopy (SEM). It demonstrates almost uniform morphologies with size in the range of 53-117 $\mathrm{nm}$ that had been used in our previous work (Alimoradzadeh et al., 2012).

\section{Results and discussion}

\subsection{Effect of operational conditions on 4-CP removal}

Several blank tests were carried out in constant concentration of 4-CP to show the removal options rather than photocatalytic processes. The data in Fig.1 presents that there is little adsorption of 4-CP (less than 4.5\%) by $\mathrm{NiO}$ alone in the absence of UV illustration. The contribution of volatilization was negligible in the removal of 4-CP from reactor. Nevertheless, all parts used in the reactor were glassware to minimize the impact of adsorption (Chiou et al., 2008). Also, it is found that $\mathrm{H}_{2} \mathrm{O}_{2}$ could not remove 4-CP alone. Similarly, Zhihui et al. (Zhihui et al., 2005) showed that the degradation of 4-CP was not affected by $\mathrm{H}_{2} \mathrm{O}_{2}$ alone. Direct photolysis of 4-CP whit UV alone leads to a moderately 4-CP removal.

It is necessary to mention that about $82 \%$ of $4-\mathrm{CP}$ is degraded within $60 \mathrm{~min}$ when $0.05 \mathrm{gl}^{-1} \mathrm{NiO}$ is added using UV/NiO process. Also, approximately complete 4-CP removal is obtained when the solution is treated 
with $0.2 \mathrm{M} \mathrm{H}_{2} \mathrm{O}_{2}$ under UV irradiation.

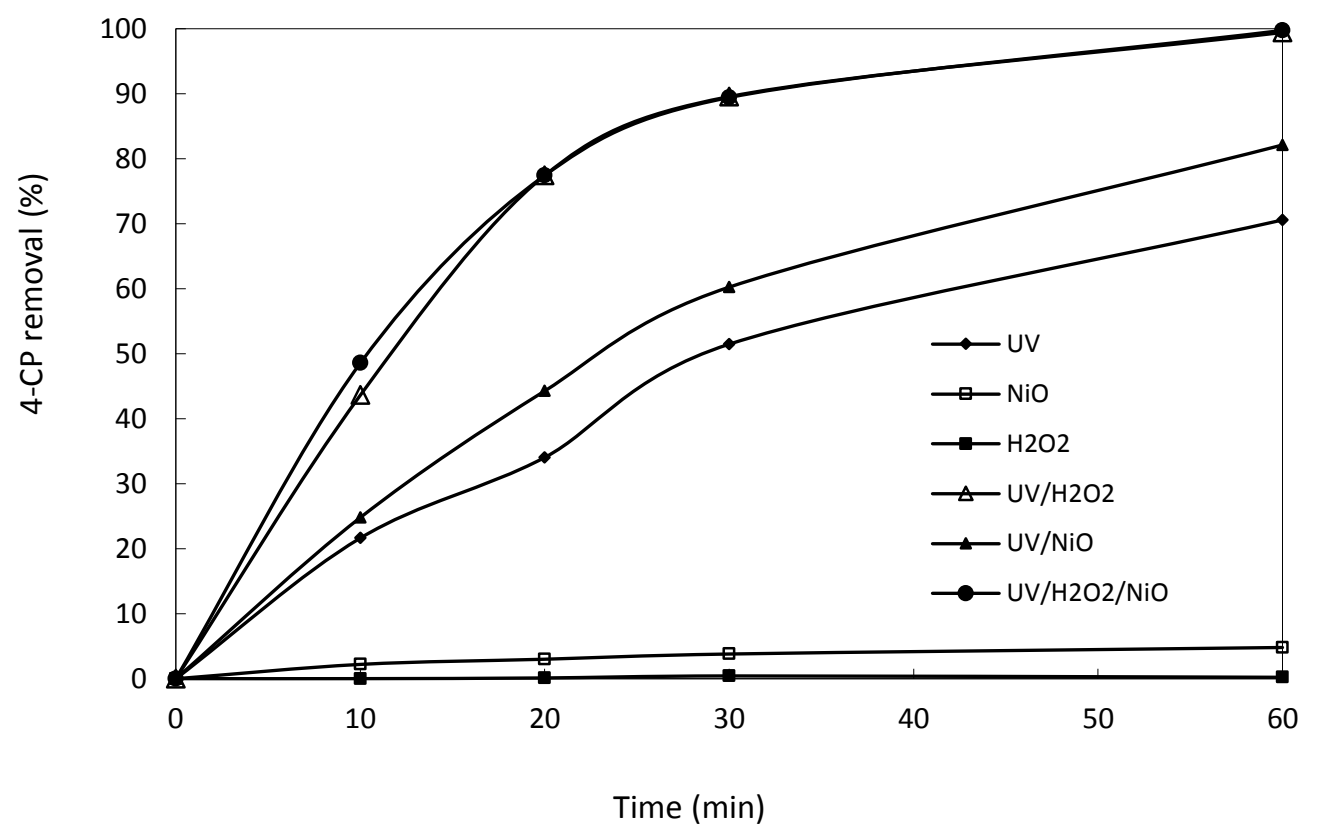

Figure 1. The effect of different reaction conditions on 4-CP removal

$$
\left(\mathrm{C}_{\mathrm{o}}=100 \mathrm{mg} \mathrm{l}^{-1}, \mathrm{H}_{2} \mathrm{O}_{2}=0.2 \mathrm{moll}^{-1}, \mathrm{NiO}=0.05 \mathrm{gl}^{-1}, \mathrm{pH}=7\right. \text { ) }
$$

On the other hand, the combination of such two processes (that is, the UV/NiO/ $\mathrm{H}_{2} \mathrm{O}_{2}$ system) further improves 4-CP removal (Fig.1). The results of study showed that photodegradation of phenol using UV/TiO $/ \mathrm{H}_{2} \mathrm{O}_{2}$ process was much more effective than using either $\mathrm{UV} / \mathrm{H}_{2} \mathrm{O}_{2}$ or $\mathrm{UV} / \mathrm{TiO} \mathrm{O}_{2}$ process (Chiou et al., 2008). Similar results by different catalysts for 4-CP removal were observed with those reported by other studies (Stoyanova et al., 2003; Lai et al., 2008; Wang et al., 2009; Lai et al., 2011).

\subsection{Mineralization of 4-CP}

Mineralization of xenobiotics is the main goal in industrial wastewater treatment facilities. Therefore, It is important to follow not only disappearance of the initial pollutant but also its mineralization into $\mathrm{CO}_{2}, \mathrm{H}_{2} \mathrm{O}$, and inorganic ions (Goel et al., 2010). Figure 2 illustrates the mineralization profile of 4-CP by variations of TOC in the different processes. The TOC data presented that the mineralization of 4-CP by UV/NiO and $\mathrm{UV} / \mathrm{H}_{2} \mathrm{O}_{2}$ at a reaction time of $60 \mathrm{~min}$ are 29.6 percent and 34.9 percent, respectively. The reduction of TOC was firstly slow and then a relatively faster degradation followed after 30 minutes in the UV/NiO system. This provides further support to previous work that 4-CP photodegradation is likely initiated by branch dissociations, benzene rings remain intact and the hydroxyl radicals produced by the system tend to react with organic molecules over the catalyst surface or in the solution released from the catalyst surface (Chiou et al., 2008). In contrast, the UV/ $\mathrm{H}_{2} \mathrm{O}_{2}$ system begins with a fast degradation and follows by retarded degradation rate. But in the UV/NiO/ $\mathrm{H}_{2} \mathrm{O}_{2}$ system, TOC removal is enhanced; with $48 \%$ of the TOC being mineralized after $60 \mathrm{~min}$ of reaction. Thus, combining $\mathrm{UV} / \mathrm{H}_{2} \mathrm{O}_{2}$ with $\mathrm{UV} / \mathrm{NiO}$ further promotes photodegradation for 4-CP than UV/ $\mathrm{H}_{2} \mathrm{O}_{2}$ or UV/NiO alone. In agreement with results of our previous work (Alimoradzadeh et al., 2012), the researchers have main reasons to consider that the NiO may be a good catalyst in UV/NiO/ $\mathrm{H}_{2} \mathrm{O}_{2}$ system.

As shown in Fig.2, the formation of $\mathrm{Cl}^{-}$ions during $\mathrm{UV} / \mathrm{NiO}, \mathrm{UV} / \mathrm{H}_{2} \mathrm{O}_{2}$, and $\mathrm{UV} / \mathrm{NiO} / \mathrm{H}_{2} \mathrm{O}_{2}$ systems were 16.39, 
20.89 , and $21.4 \mathrm{mg} \mathrm{l}^{-1}$, respectively, whereas the stoichiometric concentration of $\mathrm{Cl}^{-}$atoms initially present in the molecule of $100 \mathrm{mg} \mathrm{l}^{-1} 4-\mathrm{CP}$ are $27.6 \mathrm{mg} \mathrm{l}^{-1}$. It is seen that, by addition $\mathrm{NiO}$ catalyst to $\mathrm{UV} / \mathrm{H}_{2} \mathrm{O}_{2}$ process, the formation of $\mathrm{Cl}^{-}$ions rose to reach $80 \%$. This was due to the higher decomposition of 4-CP. On the other hand, about $52 \%$ of TOC still remained after 60 min irradiation while 4-CP was more dechlorinated and subsequent the $\mathrm{Cl}^{-}$ions were generated. It seems that the $\mathrm{Cl}^{-}$ions accounted for its inhibitory effect on NiO photocatalysis through a preferential adsorption displacement mechanism over the surface bound $\mathrm{OH}^{-}$ions. This reduces the number of $\mathrm{OH}^{-}$ions available on the NiO surface, and the substituted $\mathrm{Cl}^{-}$further increases the recombination of electron-hole pairs. In other words, the presence of $\mathrm{Cl}^{-}$as a scavenger may decrease mineralization rate (Chong et al., 2010).

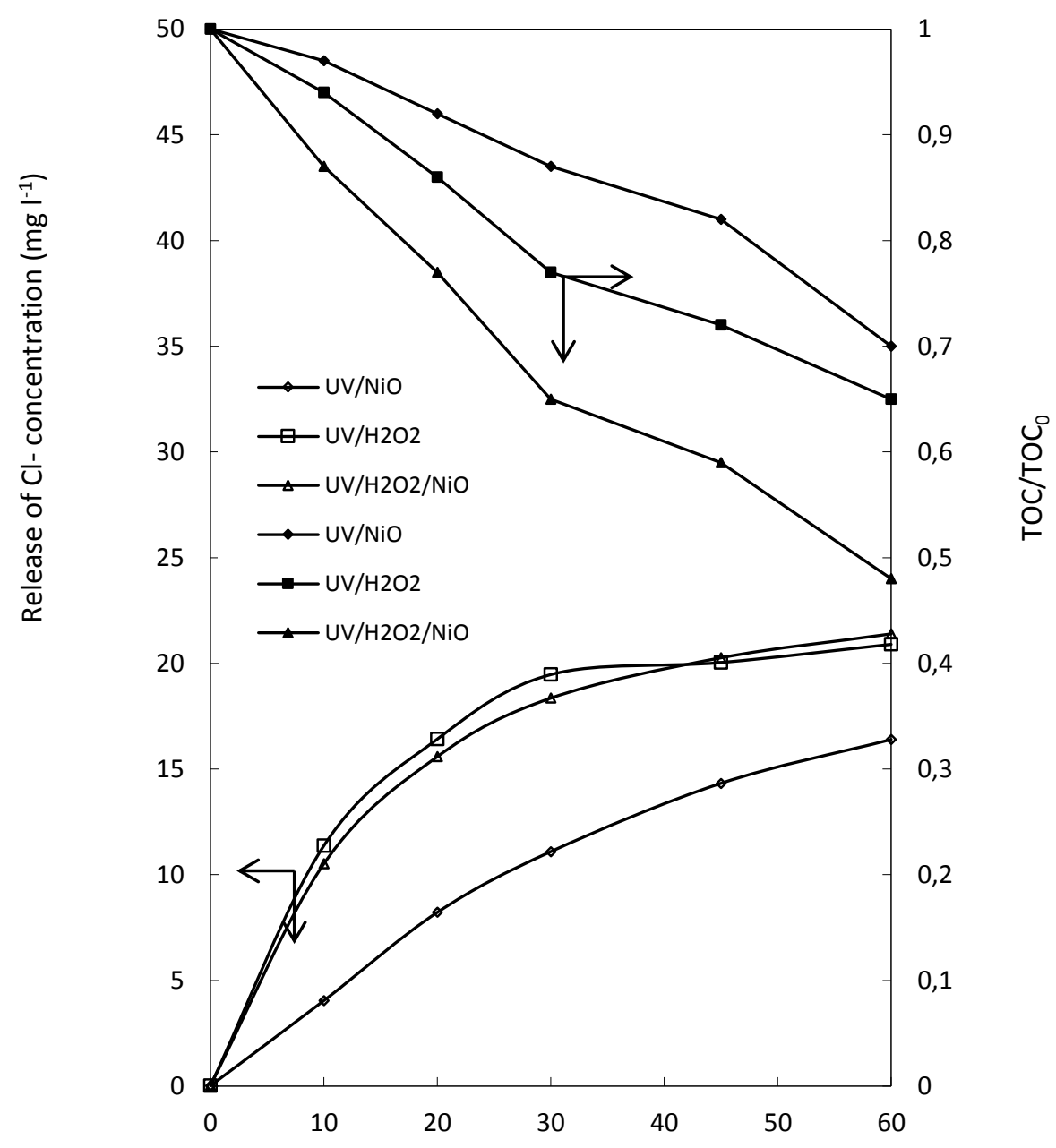

Time (min)

Figure 2. The effect of various oxidation processes on $\mathrm{TOC}$ removal and release of $\mathrm{Cl}^{-}$ions during 4-CP degradation $\left(\mathrm{C}_{\mathrm{o}}=100 \mathrm{mg} \mathrm{l}^{-1}, \mathrm{H}_{2} \mathrm{O}_{2}=0.2 \mathrm{~mol} \mathrm{l}^{-1}, \mathrm{NiO}=0.05 \mathrm{~g} \mathrm{l}^{-1}, \mathrm{pH}=7\right)$.

The variations of $\mathrm{pH}$ as other aspect of 4-CP mineralization clearly have presented in Fig. 3. 


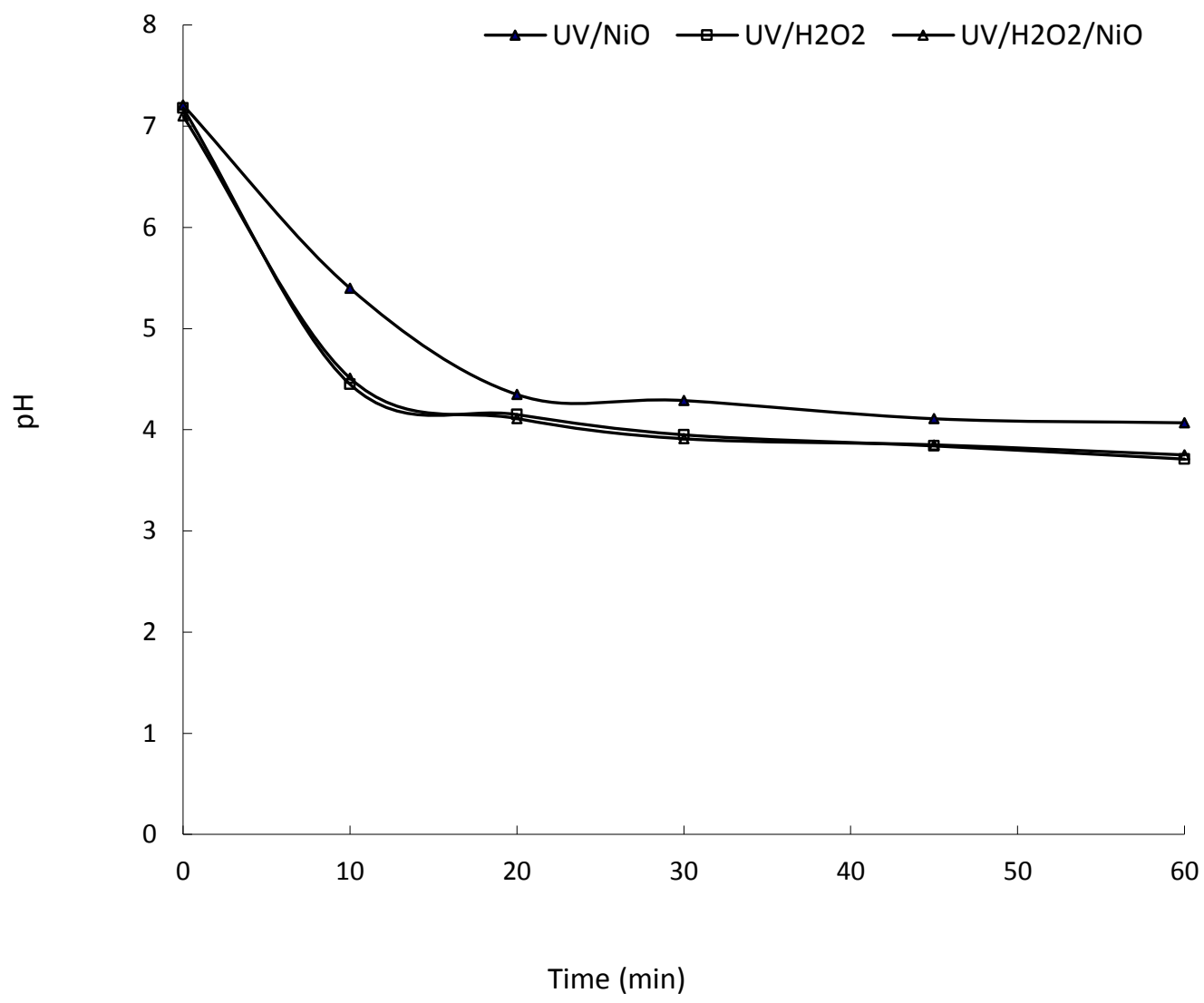

Figure 3. The variation of the initial solution $\mathrm{pH}$ on 4-CP removal using $\mathrm{UV} / \mathrm{NiO}, \mathrm{UV} / \mathrm{H}_{2} \mathrm{O}_{2}, \mathrm{UV} / \mathrm{NiO} / \mathrm{H}_{2} \mathrm{O}_{2}$ processes $\left(\mathrm{C}_{\mathrm{o}}=100 \mathrm{mg} \mathrm{l}^{-1}, \mathrm{H}_{2} \mathrm{O}_{2}=0.2 \mathrm{~mol} \mathrm{l}^{-1}, \mathrm{NiO}=0.05 \mathrm{~g} \mathrm{l}^{-1}, \mathrm{pH}=7\right)$.

Since $\mathrm{pH}$ is a main operation parameter for catalyst surface properties in aqueous solution, it is important to examine the effect of $\mathrm{pH}$. Also, the profile of $\mathrm{pH}$ variation in the reactor shows two fast and slow reduction trends at $60 \mathrm{~min}$. The most likely explanation for the variation of $\mathrm{pH}$ value could be attributed to two factors. $\mathrm{H}^{+}$is generated when water is illuminated and the $\mathrm{Cl}^{-}$ions were produced during mineralization process. It is obvious that the decrease of the $\mathrm{pH}$ value could be attributed to the generation of $\mathrm{HCl}$. The amount of organic $\mathrm{Cl}$ decreases with increasing of absorbed dose and thereby the $\mathrm{HCl}$ formation rate also decreases (Yang et al., 2007).

The loss of 4-CP was observed as function of irradiation time and data fitted to a first-order rate model according to following equation with an apparent rate constant $(k)$ :

$$
\ln \left(\frac{C}{C_{0}}\right)=-k t
$$

A plot of $-\ln (C / C o)$ versus reaction time $t$ yields a straight line, and the slope is the apparent rate constant $(k)$. It was also confirmed in this study that 4-CP photodegradation using $\mathrm{UV} / \mathrm{NiO} / \mathrm{H}_{2} \mathrm{O}_{2}$ system follows the firstorder kinetics as shown in Fig.4. 


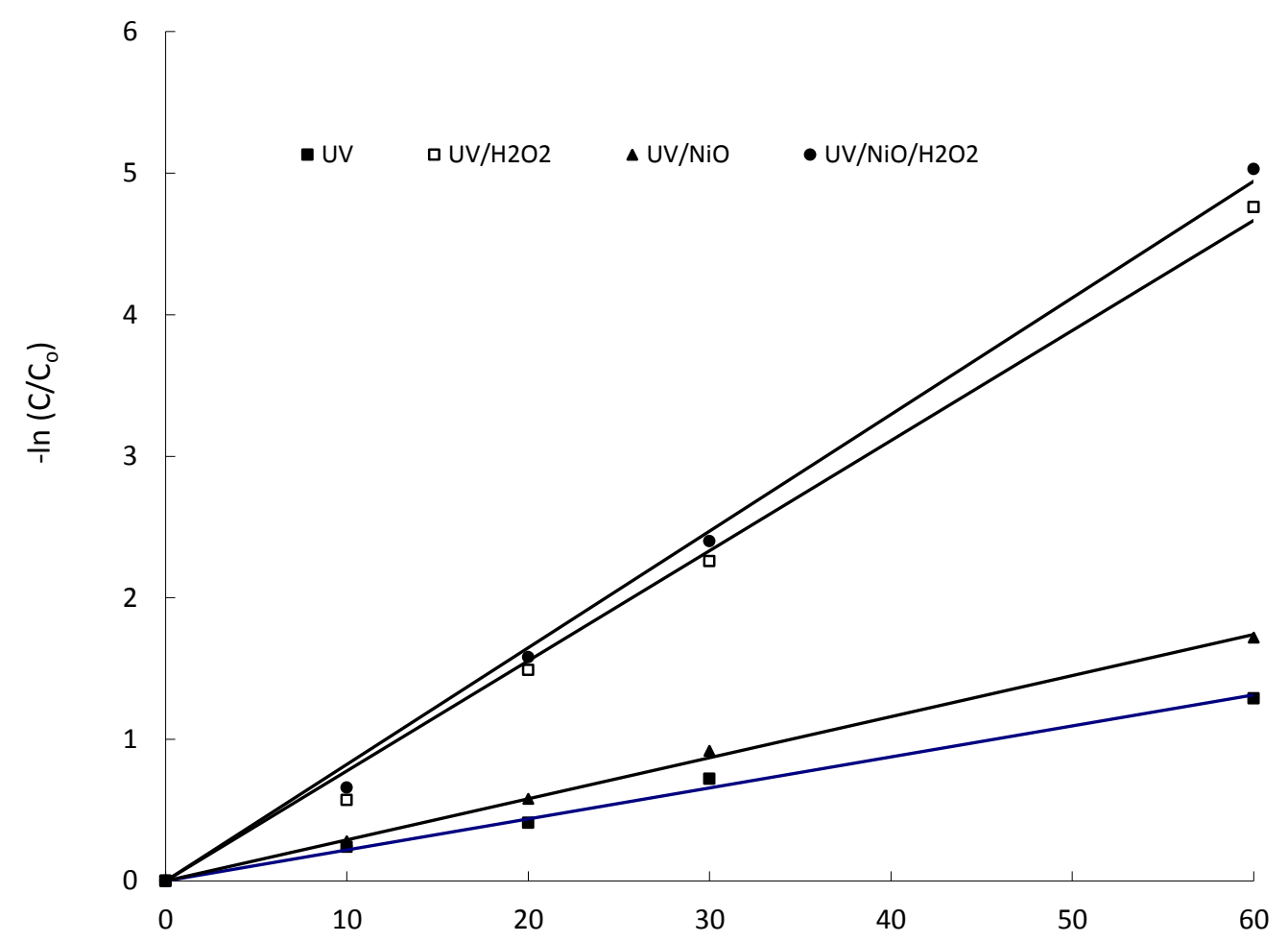

Time (min)

Figure 4. Comparison of reaction rates on different oxidation processes

$$
\left(\mathrm{C}_{\mathrm{o}}=100 \mathrm{mg} \mathrm{l}^{-1}, \mathrm{H}_{2} \mathrm{O}_{2}=0.2 \mathrm{~mol} \mathrm{I}^{-1}, \mathrm{NiO}=0.05 \mathrm{~g} \mathrm{l}^{-1}, \mathrm{pH}=7\right) \text {. }
$$

Table 1 lists the kinetic parameters for 4-CP photodegradation under various oxidation conditions. The process indicating highest $\mathrm{k}$ is $\mathrm{UV} / \mathrm{NiO} / \mathrm{H}_{2} \mathrm{O}_{2}$, approximately 2.9 times higher than the $\mathrm{UV} / \mathrm{NiO}$ and 1.1 times higher than $\mathrm{UV} / \mathrm{H}_{2} \mathrm{O}_{2}$ and the half-life time is related to the rate constant.

Table 1. First-order rate constant ( $k$ ) and half-life for 4-CP removal in various oxidation processes.

\begin{tabular}{ccccc}
\hline process & $\mathrm{k}\left(\mathrm{min}^{-1}\right)$ & Initial rate $\left(\mathrm{mg} \mathrm{min}^{-1}\right)$ & Half-life $(\mathrm{min})$ & $\mathrm{R}^{2}$ \\
\hline $\mathrm{UV}$ & 0.0003 & 1.22 & 30 & 0.994 \\
\hline $\mathrm{UV} / \mathrm{NiO}$ & 0.029 & 1.38 & 23 & 0.998 \\
\hline $\mathrm{UV} / \mathrm{H}_{2} \mathrm{O}_{2}$ & 0.077 & 1.65 & 12.5 & 0.987 \\
\hline $\mathrm{UV} / \mathrm{NiO} / \mathrm{H}_{2} \mathrm{O}_{2}$ & 0.083 & 1.66 & 10 & 0.967 \\
\hline
\end{tabular}

\subsection{Effect of NiO dosage on 4-CP removal}

To obtain the optimal NiO dosage, the investigation was performed with various amount of catalyst. Figure 5 shows the percent degradation of 4-CP as a function of the added $\mathrm{NiO}$ and the degradation rate of 4-CP distinctly increased with increasing of $\mathrm{NiO}$. It is found that $\mathrm{UV}$ irradiation in the absence of $\mathrm{NiO}$ catalyst shows low 4-CP removal (about 70\%). When NiO dosage increased to $0.05 \mathrm{~g} \mathrm{I}^{-1}$, removal of 4-CP increased to $83 \%$. 


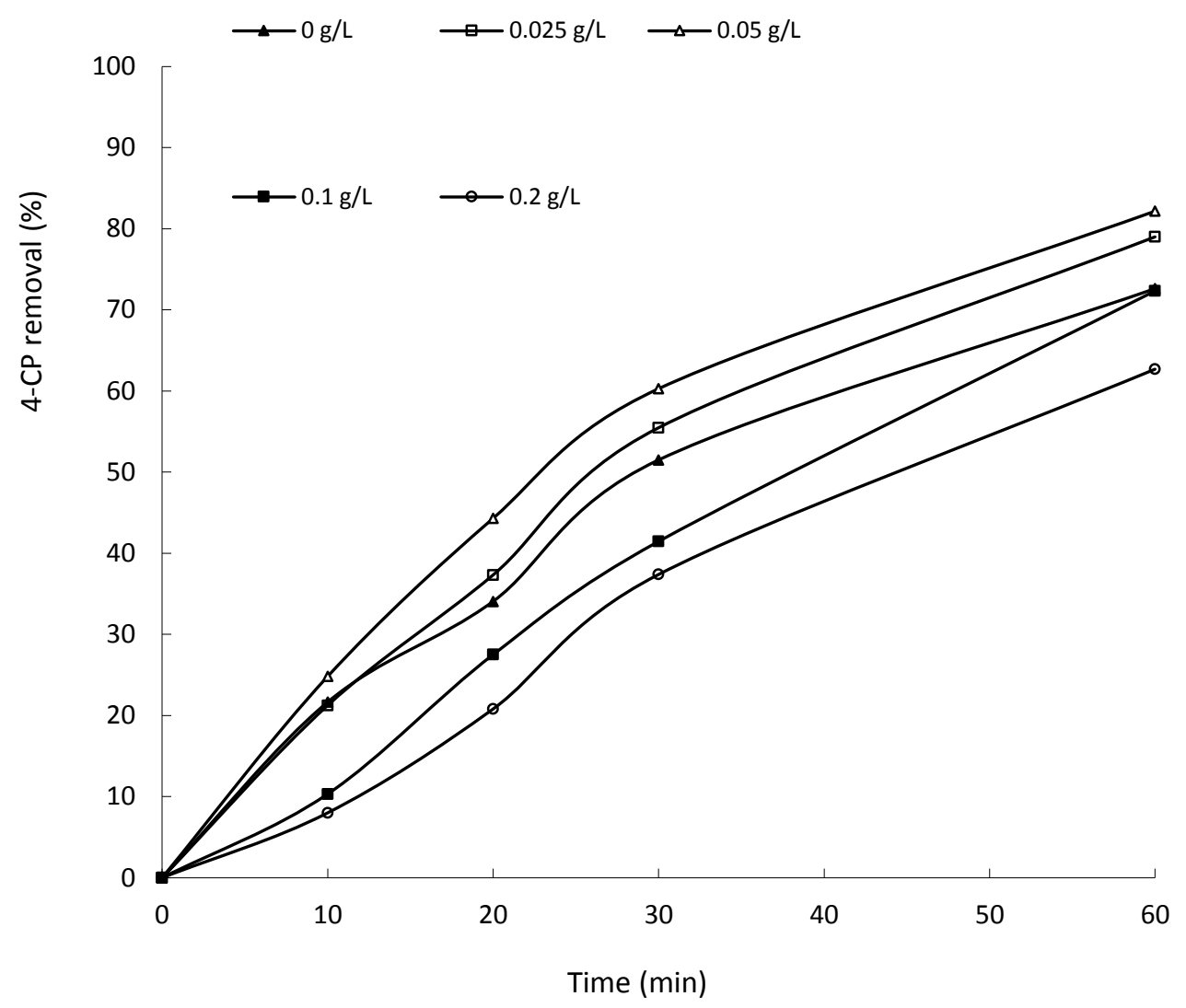

Figure 5. The effect of the dosage of $\mathrm{NiO}$ catalyst on 4-CP removal using $\mathrm{UV} / \mathrm{NiO}$ process $\left(\mathrm{C}_{0}=100 \mathrm{mg} \mathrm{l}^{-1}, \mathrm{NiO}=0.05 \mathrm{gl}^{-1}, \mathrm{pH}=7\right)$.

This indicates that 4-CP photodegradation by direct photolysis (using UV alone) is much lower than that of photocatalytic degradation by $\mathrm{NiO}$. In other words, $\mathrm{NiO}$ is capable of promoting the interaction between hydroxyl radicals and 4-CP. Many works have proved that the rates of photodegradation are strongly affected by the number of active sites and the photo-absorption ability of the catalyst used (Lathasree et al., 2004). Adequate dosage of the catalyst increases the generation rate of electron/hole pairs; therefore, the formation of $\mathrm{OH}$ radicals for promoting photodegradation. However, an overdose of the catalyst decreases the UV penetration due to opacity caused by excess catalyst clusters and at the same time increases the scattering effect (Gaya et al., 2009).

\subsection{Effect of the initial 4-CP concentration}

The effects of different 4-CP concentrations on the reaction constant rates of UV/NiO system are shown in Fig. 6.

The removal rates of 4-CP decrease with increasing $\mathrm{C}_{0}$ under the conditions studied. At a 4-CP concentration below $25 \mathrm{mg} \mathrm{l}^{-1}$, more than $90 \%$ of $4-\mathrm{CP}$ is removed within $60 \mathrm{~min}$. A first-order type of kinetic expression is still adopted here to describe the concentration effect on its photodegradation rate. The rate constants are $0.052,0.041,0.023$ and $0.019 \mathrm{~min}^{-1}$ at $\mathrm{C}_{0}$ of $25,50,100$, and $200 \mathrm{mg} \mathrm{l}^{-1}$, respectively. The present results indicate that photocatalytic oxidation is rather promising at low organic pollutant concentrations. This is also the case for heterogeneous catalytic processes where the reaction occurs at the interface between the two 
phases (Cheng et al., 2007). The main reason is that the formation of hydroxyl radical is constant for a given amount of the catalyst. Hence, the available $\mathrm{OH}$ radical are insufficient for 4-CP degradation at higher concentrations (Wang et al., 2009). Moreover, the higher the 4-CP concentration, the higher concentrations of intermediate products are produced which compete for reacting with $\mathrm{OH}$ radicals generated from surfacetrapped photogenerated holes (Gaya et al., 2009).

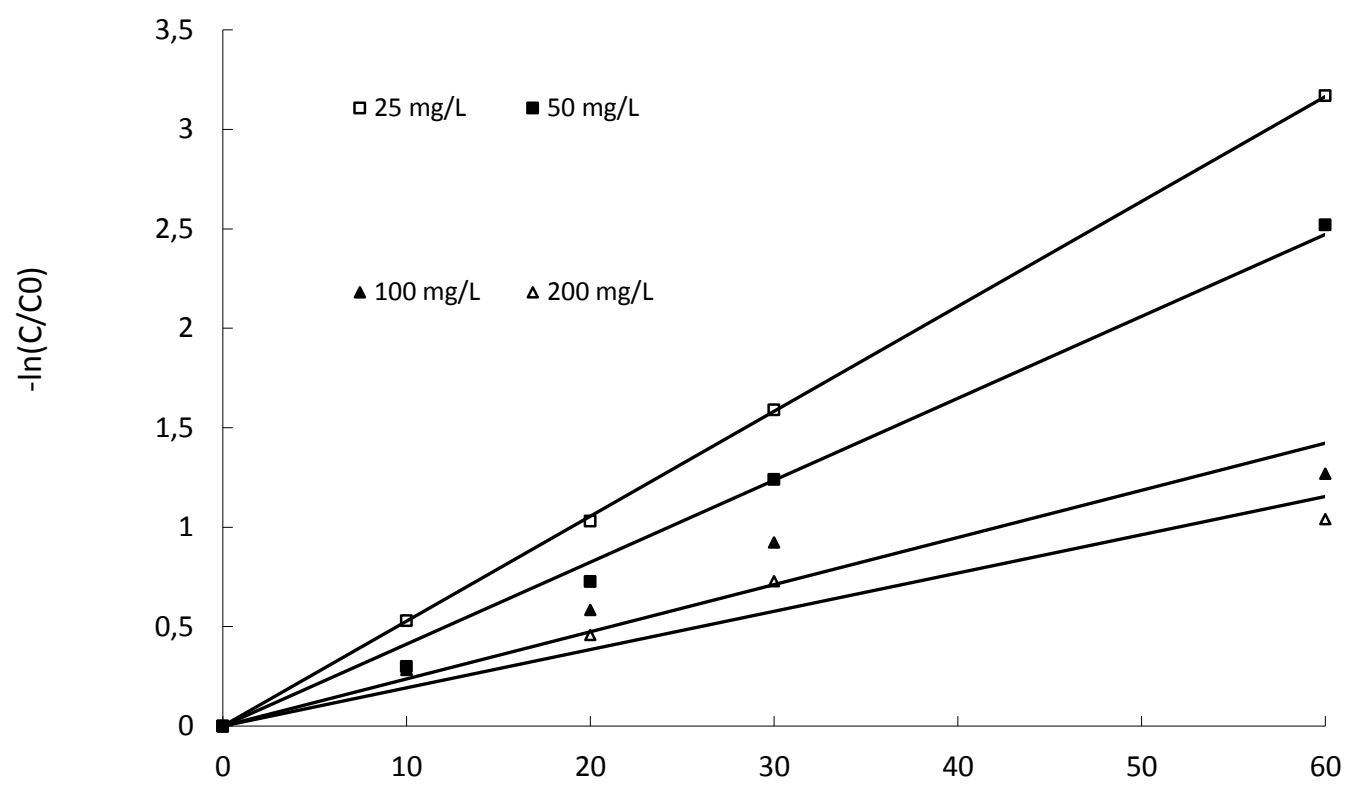

Time (min)

Figure 6. The effect of initial 4-CP concentration on constant reaction rate $(k)$ using UV/NiO process $\left(\mathrm{pH}=7, \mathrm{NiO}=0.05 \mathrm{~g} \mathrm{l}^{-1}\right)$.

\subsection{Influence of solution $\mathrm{pH}$}

Figure 7 shows the effect of $\mathrm{pH}$ on the degradation of 4-CP $\left(C_{0}=100 \mathrm{mg} \mathrm{l}^{-1}\right)$ in the UV/NiO system. The pH of the solution dominates photodegradation process due to the strongly $\mathrm{pH}$ dependent of the properties such as semiconductor's surface charge state, flat band potential, and dissociation of the solution (Doong et al., 2001). The UV/NiO process demonstrates that the degradation of 4-CP is independent of $\mathrm{pH}$ and relatively low effect was observed in the range of 4-10 at $60 \mathrm{~min}$ reaction time. Although, little decreasing was observed in acidic $\mathrm{pH}$. The best results were obtained at basic $\mathrm{pH}$.

As shown in Fig.7, the fastest rate of 4-CP degraded occurs within 10 min under different $\mathrm{pH}$ values (degree of conversion obtains $33.2 \%$ for $\mathrm{pH} 10$ but $24.8 \%$ for $\mathrm{pH} 7$ and $12.7 \%$ for $\mathrm{pH} 4$ ). The most likely reason for this observation is the very low substantial loss of $\mathrm{NiO}$ to $\mathrm{Ni}^{+2}$ at low $\mathrm{pH}$ value (Stoyanova et al., 2003). The removal rate increase at higher $\mathrm{pH}$ value due to $\mathrm{NiO}$ stability is less disturbed. This provide further support to earlier work that 4-CP can be totally removed in the $\mathrm{pH}$ range of 4-10 in $30 \mathrm{~min}$ by $\mathrm{MW} / \mathrm{NiO}$ system (Lai et al., 2007). In contrast, the findings of other works with different catalyst, $\mathrm{ZnO}$ (Gaya et al., 2009), P-25 $\mathrm{TiO}_{2}, \mathrm{TiO}_{2}$ nanofibers, tin-doped $\mathrm{TiO}_{2}$ nanofibers, and coumarin (C-343) coated $\mathrm{TiO}_{2}$ nanofibers (Ghosh et al., 2009), 
$\mathrm{TiO}_{2}, \mathrm{WO}_{3}, \mathrm{SnO}_{2}, \mathrm{TiO}_{2} / \mathrm{WO}_{3}$ and $\mathrm{TiO}_{2} / \mathrm{SnO}_{2}$ systems have shown that $\mathrm{pH}$ affects significantly the photocatalytic degradation of 4-CP or production of hydroxyl radical (Lin et al., 2008).

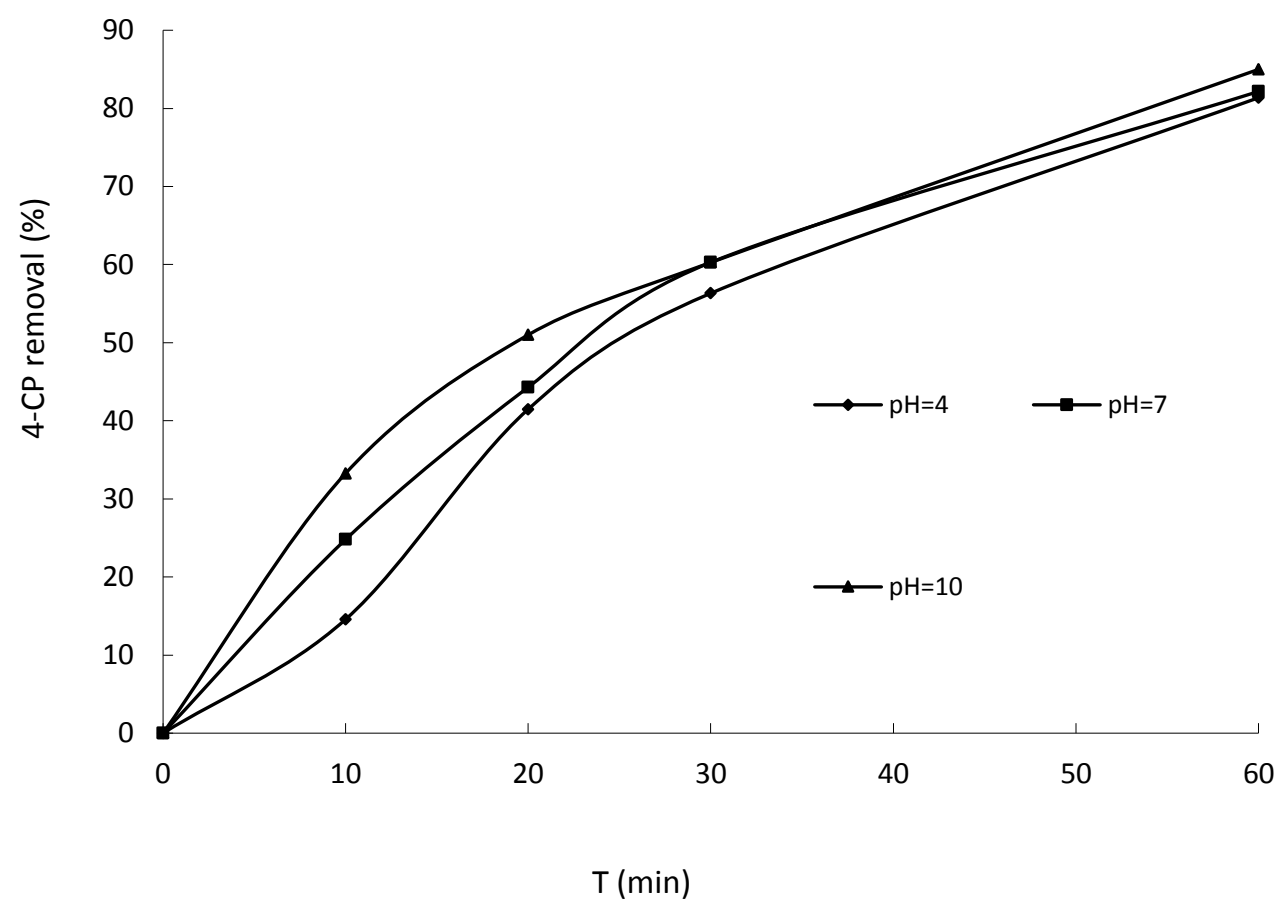

Figure 7. 4-CP degradation as a function of the $\mathrm{pH}$ value in the UV/NiO system $\left(\mathrm{Co}=100 \mathrm{mg} \mathrm{l}^{-1}, \mathrm{NiO}=0.05 \mathrm{~g}^{-1}\right)$.

\section{Conclusions}

Photodegradation with UV/NiO process was indicated that the complete removal of 4-CP could be achieved at different operating condition. The first-order rate constant increased nearly three-fold compared to the absence of $\mathrm{H}_{2} \mathrm{O}_{2}$. The present results indicated that photodegradation of 4-CP using $\mathrm{NiO}$ was best achieved near neutral $\mathrm{pH}$. Unlike the complete degradation of 4-CP by $0.05 \mathrm{~g} \mathrm{I}^{-1} \mathrm{NiO}$ and $0.2 \mathrm{M} \mathrm{H}_{2} \mathrm{O}_{2}$ within 60 min based on 4-CP concentration data, the TOC of the solution was reduced by $48 \%$ only within 60 min. Moreover, the results of mineralization and chloride ions studies indicated that dechlorination was better accomplished, but more time was required to completely mineralize 4-CP into $\mathrm{H}_{2} \mathrm{O}$ and $\mathrm{CO}_{2}$. Finally, the efficient degradation of 4-CP observed in this study suggests that the UV/NiO process is a potentially useful method for the removal of xenobiotics in aqueous environment.

\section{Acknowledgements}

The authors wish to express their gratitude for the financial support of research and technology vice chancellor of the Zanjan University of Medical Sciences.

\section{References}

Aguedach A., Brosillon S., Morvan J. and Lhadi E.K. (2005), Photocatalytic degradation of azo-dyes reactive black 5 and 
reactive yellow 145 in water over a newly deposited titanium dioxide, Applied Catalysis B: Environmental, 57(1), 55-62.

Alimoradzadeh R., Assadi A., Nasseri S. and Mehrasbi M.R. (2012), Photocatalytic degradation of 4-chlorophenol by $\mathrm{UV} / \mathrm{H} 2 \mathrm{O} 2 / \mathrm{NiO}$ process in aqueous solution, Iranian Journal of Environmental Health Science \& Engineering, 9(1), 1-8.

Catrinescu C., Arsene D. and Teodosiu C. (2011), Catalytic wet hydrogen peroxide oxidation of para-chlorophenol over Al/Fe pillared clays (AIFePILCs) prepared from different host clays, Applied Catalysis B: Environmental, 101(3-4), 451-460.

Cheng Y., Sun H., Jin W. and Xu N. (2007), Photocatalytic degradation of 4-chlorophenol with combustion synthesized TiO2 under visible light irradiation, Chemical Engineering Journal, 128(2-3), 127-133.

Chiou C.-H., Wu C.-Y. and Juang R.-S. (2008), Influence of operating parameters on photocatalytic degradation of phenol in UV/TiO 2 process, Chemical Engineering Journal, 139(2), 322-329.

Chong M.N., Jin B., Chow C.W.K. and Saint C. (2010), Recent developments in photocatalytic water treatment technology: A review, Water Research, 44(10), 2997-3027.

Devulapelli V.G. and Sahle-Demessie E. (2008), Catalytic oxidation of dimethyl sulfide with ozone: Effects of promoter and physico-chemical properties of metal oxide catalysts, Applied Catalysis A: General, 348(1), 86-93.

Doong R.-A., Chen C.-H., Maithreepala R.A. and Chang S.-M. (2001), The influence of pH and cadmium sulfide on the photocatalytic degradation of 2-chlorophenol in titanium dioxide suspensions, Water Research, 35(12), 2873-2880.

Du Y., Fu Q.S., Li Y. and Su Y. (2011), Photodecomposition of 4-chlorophenol by reactive oxygen species in UV/air system, Journal of Hazardous Materials, 186(1), 491-496.

Gaya U.I., Abdullah A.H., Zainal Z. and Hussein M.Z. (2009), Photocatalytic treatment of 4-chlorophenol in aqueous ZnO suspensions: Intermediates, influence of dosage and inorganic anions, Journal of Hazardous Materials, 168(1), 57-63.

Ghosh J.P., Sui R., Langford C.H., Achari G. and Berlinguette C.P. (2009), A comparison of several nanoscale photocatalysts in the degradation of a common pollutant using LEDs and conventional UV light, Water Research, 43(18), 44994506.

Gimeno O., Carbajo M., Beltrán F.J. and Rivas F.J. (2005), Phenol and substituted phenols AOPs remediation, Journal of Hazardous Materials, 119(1-3), 99-108.

Goel M., Chovelon J.-M., Ferronato C., Bayard R. and Sreekrishnan T.R. (2010), The remediation of wastewater containing 4-chlorophenol using integrated photocatalytic and biological treatment, Journal of Photochemistry and Photobiology B: Biology, 98(1), 1-6.

Gomez M., Matafonova G., Gomez J.L., Batoev V. and Christofi N. (2009), Comparison of alternative treatments for 4chlorophenol removal from aqueous solutions: Use of free and immobilized soybean peroxidase and $\mathrm{KrCl}$ excilamp, Journal of Hazardous Materials, 169(1-3), 46-51.

He H., Yang S., Yu K., Ju Y., Sun C. and Wang L. (2010), Microwave induced catalytic degradation of crystal violet in nanonickel dioxide suspensions, Journal of Hazardous Materials, 173, 393-400.

Lai T.-L., Liu J.-Y., Yong K.-F., Shu Y.-Y. and Wang C.-B. (2008), Microwave-enhanced catalytic degradation of 4chlorophenol over nickel oxides under low temperature, Journal of Hazardous Materials, 157(2-3), 496-502.

Lai T.-L., Wang W.-F., Shu Y.-Y., Liu Y.-T. and Wang C.-B. (2007), Evaluation of microwave-enhanced catalytic degradation of 4-chlorophenol over nickel oxides, Journal of Molecular Catalysis A: Chemical, 273(1-2), 303-309.

Lai T.-L., Yong K.-F., Yu J.-W., Chen J.-H., Shu Y.-Y. and Wang C.-B. (2011), High efficiency degradation of 4-nitrophenol by microwave-enhanced catalytic method, Journal of Hazardous Materials, 185(1), 366-372.

Laoufi N., Tassalit D. and Bentahar F. (2008), The degradation of phenol in water solution by $\mathrm{TiO}_{2}$ photocatalysis in a helical reactor, Global NEST Journal, 10(3), 404-418.

Lathasree S., Rao A.N., SivaSankar B., Sadasivam V. and Rengaraj K. (2004), Heterogeneous photocatalytic mineralisation of phenols in aqueous solutions, Journal of Molecular Catalysis A: Chemical, 223(1-2), 101-105. 
Li J.-M., Meng X.-G., Hu C.-W., Du J. and Zeng X.-C. (2009), Oxidation of 4-chlorophenol catalyzed by Cu(II) complexes under mild conditions: Kinetics and mechanism, Journal of Molecular Catalysis A: Chemical, 299(1-2), 102-107.

Lin C.-F., Wu C.-H. and Onn Z.-N. (2008), Degradation of 4-chlorophenol in $\mathrm{TiO}_{2}, \mathrm{WO}_{3}, \mathrm{SnO}_{2}, \mathrm{TiO}_{2} / \mathrm{WO}_{3} \mathrm{and} \mathrm{TiO}_{2} / \mathrm{SnO}_{2}$ systems, Journal of Hazardous Materials, 154(1-3), 1033-1039.

Lo S.-C., Lin C.-F., Wu C.-H. and Hsieh P.-H. (2004), Capability of coupled CdSe/TiO2 for photocatalytic degradation of 4chlorophenol, Journal of Hazardous Materials, 114(1-3), 183-190.

Movahedyan H., Assadi A. and Amin M.M. (2008), Effects of 4-chlorophenol loadings on acclimation of biomass with optimized fixed time sequencing batch reactor, Iranian Journal of Environmental Health Science and Engineering, 5(4), 225-234.

Neppolian B., Ciceri L., Bianchi C.L., Grieser F. and Ashokkumar M. (2011), Sonophotocatalytic degradation of 4chlorophenol using $\mathrm{Bi}_{2} \mathrm{O}_{3} / \mathrm{TiZrO}_{4}$ as a visible light responsive photocatalyst, Ultrason. Sonochem., 18(1), $135-139$.

Olaniran A.O. and Igbinosa E.O. (2011), Chlorophenols and other related derivatives of environmental concern: Properties, distribution and microbial degradation processes, Chemosphere, 83(10), 1297-1306.

Patil P.S. and Kadam L.D. (2002), Preparation and characterization of spray pyrolyzed nickel oxide (NiO) thin films, Applied Surface Science, 199(1-4), 211-221.

Pera-Titus M., García-Molina V., Baños M.A., Giménez J. and Esplugas S. (2004), Degradation of chlorophenols by means of advanced oxidation processes: a general review, Applied Catalysis B: Environmental, 47(4), 219-256.

Pi Y., Zhang L. and Wang J. (2007), The formation and influence of hydrogen peroxide during ozonation of parachlorophenol, Journal of Hazardous Materials, 141(3), 707-712.

Stasinakis A. (2008), Use of selected advanced oxidation processes (AOPs) for wastewater treatment-a mini review, Global NEST Journal, 10(3), 376-385.

Stoyanova M. and Christoskova S. (2011), Catalytic degradation of methylene blue in aqueous solutions over Ni- and Cooxide systems, Central European Journal of Chemistry, 9(6), 1000-1007.

Stoyanova M., Christoskova S. and Georgieva M. (2003), Mixed Ni-Mn-oxide systems as catalysts for complete oxidation: Part I. Preparation and characterization, Applied Catalysis A: General, 249(2), 285-294.

Stoyanova M., Konova P., Nikolov P., Naydenov A., Christoskova S. and Mehandjiev D. (2006), Alumina-supported nickel oxide for ozone decomposition and catalytic ozonation of CO and VOCs, Chemical Engineering Journal, 122(1-2), 41-46.

Wang N., Li X., Wang Y., Quan X. and Chen G. (2009), Evaluation of bias potential enhanced photocatalytic degradation of 4-chlorophenol with $\mathrm{TiO}_{2}$ nanotube fabricated by anodic oxidation method, Chemical Engineering Journal, 146(1), 30-35.

Yang R., Wang M., Shen Z., Wang W., Ma H. and Gu J. (2007), The degradation and mineralization of 4-chlorophenol in aqueous solutions by electron beam irradiation in the presence of $\mathrm{TiO}_{2}$ nanoparticles, Radiation Physics and Chemistry, 76(7), 1122-1125.

Zhang X., Li X. and Qin W. (2009), Investigation of the catalytic activity for ozonation on the surface of NiO nanoparticles, Chemical Physics Letters, 479(4-6), 310-315.

Zhihui A., Peng Y. and Xiaohua L. (2005), Degradation of 4-Chlorophenol by microwave irradiation enhanced advanced oxidation processes, Chemosphere, 60(6), 824-827. 